\title{
Enantioselective Addition of Grignard Reagents to Aldehydes
}

\author{
Pablo Englebienne, Hernan Schulz and Norma Nudelman \\ Departamento de Química Orgánica, Facultad de Ciencias Exactas y Naturales, Universidad de Buenos \\ Aires. Pabellón II, Piso 3. Ciudad Universitaria. 1428. Buenos Aires, Argentina \\ E-mail: nudelman@qo.fcen.uba.ar
}

\begin{abstract}
The addition of Grignard reagents to aldehydes in the presence of chiral aminoalcohols shows a moderate enantioselectivity. The study carried out with a series of ligands allows the correlation between the structural characteristics and their reactivity.
\end{abstract}

\section{Introduction}

The use of chiral aminoalcohol to lead asymmetrically nucleophilic additions of organometallics to carbonyl compounds is a field of great potentiality in synthesis [1]. It is based on the coordination of amines and ethers to organolithium and Grignard reagents; the efficiency of the asymmetric induction depends, among other factors, on the characteristics of the metal [2], its aggregation state [3] and on the chiral ligand structure [4].

\section{Experimental}

\section{General Procedure}

To a mixture of $1 \mathrm{mmol}$ of aldehyde and the corresponding amount of chiral ligand in the reaction solvent, $1.7 \mathrm{~mL}$ of a $0.6 \mathrm{M}$ of $\mathrm{PrMgBr}$ in the same solvent were added at $-78^{\circ} \mathrm{C}$. The quenching was carried out using $1 \mathrm{~mL}$ of $\mathrm{HCl} 5 \%$. The products in the reaction mixture were investigated by GC and polarimetry.

\section{Results and Discussion}

The addition of PrMgBr to 3-phenylpropanal, 1, and benzaldehyde, 2, was carried out in the presence of asymmetric ligands derived from 2-aminobutanol and ephedrine in different solvents and reagent:ligand:substrate ratio (see Table ). Several new ligands were designed and synthesized. 
Table. Reactions of PrMgBr with 3-phenylpropanal, 1, and benzaldehyde, $\mathbf{2}$, in the presence of chiral ligands.

\begin{tabular}{ccccccc}
\hline $\begin{array}{c}\text { Chiral } \\
\text { Ligand }^{\text {a }}\end{array}$ & $\begin{array}{c}\text { Alde- } \\
\text { hyde }\end{array}$ & $\begin{array}{c}\text { Reagent:Ligand: } \\
\text { Aldehyde ratio }\end{array}$ & Solvent & $\begin{array}{c}\text { Yield } \\
(\boldsymbol{\%})\end{array}$ & $\begin{array}{c}\text { Absolute Con- } \\
\text { figuration }\end{array}$ & $\begin{array}{c}\text { \% } \\
\text { ee }\end{array}$ \\
\hline $\mathbf{3}$ & $\mathbf{1}$ & $1.2: 0.2: 1.0$ & toluene & 77 & $\mathrm{~S}-(+)$ & 5 \\
\hline $\mathbf{4}$ & $\mathbf{1}$ & $2.0: 0.5: 1.0$ & ether & 98 & $\mathrm{R}-(-)$ & 2 \\
\hline $\mathbf{5}$ & $\mathbf{1}$ & $1.2: 0.2: 1.0$ & toluene & 98 & $\mathrm{~S}-(+)$ & 5 \\
& $\mathbf{1}$ & $1.2: 0.2: 1.0$ & ether & 100 & $\mathrm{~S}-(+)$ & 7 \\
\hline $\mathbf{6}$ & $\mathbf{2}$ & $4.0: 2.0: 1.0$ & THF & 98 & $\mathrm{R}-(+)$ & 3 \\
\hline $\mathbf{7}$ & $\mathbf{1}$ & $4.0: 2.0: 1.0$ & THF & 90 & $\mathrm{~S}-(+)$ & 8 \\
& $\mathbf{1}$ & $6.0: 2.0: 1.0$ & toluene & 85 & $\mathrm{~S}-(+)$ & 29 \\
\hline $\mathbf{8}$ & $\mathbf{2}$ & $6.0: 2.0: 1.0$ & toluene & 51 & $\mathrm{~S}-(-)$ & 40 \\
\hline $\mathbf{9}$ & $\mathbf{2}$ & $4.0: 2.0: 1.0$ & THF & 60 & $\mathrm{R}-(+)$ & 9 \\
\hline $\mathbf{3}$ & $\mathbf{1}$ & $3.0: 1.0: 1.0$ & toluene & 96 & $\mathrm{R}-(-)$ & 2 \\
\hline
\end{tabular}

${ }^{\mathrm{a}} \mathbf{3}=$ (-)-2-dipropylaminobutanol, 4 = (-)-(1-benciloxymethylpropyl)-dipropylamine, $\mathbf{5}=(-)$-4-ethyl2,2-dimethyl-oxazolidine, 6 = (-)-ephedrine, 7 = (-)-pseudoephedrine, $8=(-)$-2,2,3,4-tetramethyl-5phenyl-oxazolidine, $9=(-)-\mathrm{N}$-propylephedrine.

Several conclusions can be extracted from this table:

- Donor solvents influence negatively the effectivity of the asymmetric catalysis, likely because these solvents compete in the coordination of the attacking reagent.

- The ligands with two asymmetric centers have higher effect in the asymmetric addition. The substitution by bigger groups in the nitrogen leads to lower selectivities.

- The use of oxazolidines does not lead to fine enantiomeric excess, probably due to the conformational rigidity.

- The asymmetric induction in the formation of aromatic secondary alcohols is more pronounced than in the aliphatic secondary alcohols.

Acknowledgements: H.S. is a grateful recipient of a fellowship from the Universidad de Buenos Aires. Financial support from the UBA, CONICET, ANPCyT and the CEE is gratefully acknowledged.

\section{References and Notes}

1. Hoppe, D.; Hense, T. Angew. Chem., Int. Ed. Engl. 1997, 36, 2282.

2. Yanagisawa, A.; Nakashima, H.; Ishiba, A.; Yamamoto, H. J. Am. Chem. Soc. 1996, 118, 4723.

3. Nudelman, N. S.; Schulz, H. G.; García, G. V. J. Phys. Org. Chem. 1998, 11, 722.

4. Prasad, K. R. K. ; Joshi, N. N. J. Org. Chem. 1997, 62, 3770. 